Article

\title{
Rapid Biogas Production by Compact Multi-Layer Membrane Bioreactor: Efficiency of Synthetic Polymeric Membranes
}

\author{
Supansa Youngsukkasem ${ }^{1, *}$, Hamidreza Barghi ${ }^{1,2}$, Sudip K. Rakshit ${ }^{3}$ \\ and Mohammad J. Taherzadeh ${ }^{1}$
}

1 School of Engineering, University of Borås, 50190 Borås, Sweden;

E-Mails: hamidreza.barghi@hb.se (H.B.); mohammad.taherzadeh@hb.se (M.J.T.)

2 Department of Chemical and Biological Engineering, Chalmers University of Technology, 41296 Gothenburg, Sweden

3 Department of Chemical Engineering, Lakehead University, 955 Oliver Road, Thunder Bay, ON P7B 5E1, Canada; E-Mail: srakshit@lakeheadu.ca

* Author to whom correspondence should be addressed; E-Mail: supansa.youngsukkasem@hb.se; Tel.: +46-33-435-4608; Fax: +46-33-435-4008.

Received: 26 September 2013; in revised form: 15 November 2013 / Accepted: 21 November 2013 / Published: 28 November 2013

\begin{abstract}
Entrapment of methane-producing microorganisms between semi-permeable synthetic membranes in a multi-layer membrane bioreactor (MMBR) was studied and compared to the digestion capacity of a free-cell digester, using a hydraulic retention time of one day and organic loading rates (OLR) of 3.08, 6.16, and $8.16 \mathrm{~g} \mathrm{COD/L} \cdot$ day. The reactor was designed to retain bacterial cells with uprising plug flow through a narrow tunnel between membrane layers, in order to acquire maximal mass transfer in a compact bioreactor. Membranes of hydrophobic polyamide 46 (PA) and hydroxyethylated polyamide 46 (HPA) as well as a commercial membrane of polyvinylidene fluoride (PVDF) were examined. While the bacteria in the free-cell digester were washed out, the membrane bioreactor succeeded in retaining them. Cross-flow of the liquid through the membrane surface and diffusion of the substrate through the membranes, using no extra driving force, allowed the bacteria to receive nutrients and to produce biogas. However, the choice of membrane type was crucial. Synthesized hydrophobic PA membrane was not effective for this purpose, producing 50-121 mL biogas/day, while developed HPA membrane and the reference PVDF were able to transfer the nutrients and metabolites while retaining the cells, producing 1102-1633 and 1016-1960 mL biogas/day, respectively.
\end{abstract}


Keywords: membrane bioreactor; biogas; synthetic membrane; methane; anaerobic digestion; polyamide; PVDF; cell entrapment

\section{Introduction}

Biogas or biomethane is a renewable energy source with several applications, e.g., car fuel, heating, cooking, or electricity production. Biogas is produced worldwide through anaerobic digestion of sewage sludge and other sources, such as food wastes and landfill contents. The main components of biogas are methane and carbon dioxide, but it may also contain minor impurities, such as $\mathrm{H}_{2} \mathrm{~S}_{\text {or }} \mathrm{N}_{2}$, depending on the raw materials and the process used [1]. The anaerobic digestion process subsequent methane production comprises hydrolysis, acidogenesis, acetogenesis, and methanogenesis. The doubling time of the hydrolysis and acidogenesis bacteria is 1.0-1.5 days, while acetogens and methanogens need 1-4 and 5-15 days for doubling, respectively [2]. This implies that methane-producing microorganisms require a long retention time, and there is a risk of bacteria washing out from the digester. In addition, the methanogens are very sensitive to the process conditions, and their low growth rate results in a relatively long start-up period of up to 3 months [1]. Furthermore, a low dilution rate of the methane-producing microorganisms in the digester, or early withdrawal of the digesting bacteria, reduces the population size of these bacteria significantly; and consequently, the digestion process and biogas production would not further continue. Retaining the microorganisms inside the digester by entrapment might be an appropriate solution to overcome these problems.

Membrane bioreactors (MBRs), recently developed for wastewater treatment, is one of the solutions used to retain the bacteria inside the reactors [3]. Employing MBR has been investigated using different configurations and processes [4-7]. A laboratory-scale submerged MBR was tested using mesophilic microorganisms with different solid retention times for continuous hydrogen production. It was found that the stability of the MBR and the hydrogen content were very good when the solid (cell mass) retention time (SRT) was increased [8]. In addition, a laboratory-scale submerged MBR was studied, operated and compared to a continuously stirred tank reactor (CSTR) in order to study the performance of the reactor for hydrogen production using anaerobic mixed bacteria. The results revealed that the MBR had better performance than the CSTR and produced more hydrogen gas [9]. Using the MBR process leads to a very stable process with the possibility of reducing the demand of high reactor volumes compared to conventional digesters. Jeong et al. [10] reported the successful use of a submerged anaerobic membrane bioreactor (SAMBR) in a two-phase anaerobic digestion system for effluent treatment of high strength organic waste with improved methane production. Other types of MBRs have also been employed. For instance, swine manure was treated for biogas production with an laboratory-scale anaerobic bioreactor equipped with an external ultrafiltration membrane module [11]. Such systems are generally equipped with only one membrane layer, providing a limited membrane surface area, but may also use additional supplementary compartments, containing different kinds of membranes. Furthermore, these additional membranes need to be frequently washed to enhance the cross flow, which recycles the trapped microorganisms back to the digester. 
In previous studies, hydrophobic membrane surfaces frequently exhibited bio-fouling, most likely because of electrostatic interactions between the biomass and the membrane surface. Hydrophobic microorganisms grew in the presence of nutrients, leading to accumulation of biomass and deposition of exhausted metabolites spread on the membrane surface [12]. Hydrophilic membranes, on the other hand, might be less prone to cause bio-fouling on the membrane surface, since they will repel the cell culture [13]. Cellulosic hydrophilic membranes have been favored in membrane bioreactors for ethanol production [14,15]. They are, however, not suitable for digestion processes [16,17] due to their low stability in harsh digesting conditions. Recently, polyvinylidine fluoride (PVDF) membrane modules were applied in bioreactors in order to prevent wash-out of the microorganisms and biomass separation. Due to its high resistance against hydrolyzing, this type of membrane is used in wastewater treatment industries [13]. However, there are some issues that hinder the usage of membranes in the biogas production area. To expand the applications of synthetic membranes for biogas production, it is necessary to develop new membranes that have both excellent permeability to biogas and perm-selectivity towards the substrate. We have detected no report in the literature on using digesting bacteria encased in a compact multi-layer membrane bioreactor via employing a novel synthetic membrane of polyamide as a supporting material for biogas production.

The scope of the present work encompassed the introduction of a new design of multi-layer membrane bioreactors (MMBR) in a digestion process for biogas production as well as to investigate a new type of proactive hydrophilized polyamide 46 (synthetic membrane), used to entrap methane-producing microorganisms in the bioreactor for biogas production. Long term digestion processes in the second stage of the anaerobic digestion system, with different organic loading rates, were performed. The total volume of biogas, the total amount of volatile fatty acid and the morphology of the synthetic membranes were determined.

\section{Results and Discussion}

Biogas is one of the oldest biological products in the world, and holds a great potential to substitute at least part of the global oil consumption. A long retention time of, for example, 30 days is sometimes a challenge in anaerobic digestion processes, resulting in large digestion reactors and challenging their economic feasibility. In this work, the efficiency of compact multi-layer membrane bioreactor (MMBR) and synthetic membranes used to entrap microorganisms at different feeding rates of synthetic wastewater was investigated, and compared with free cells in a long-term, semi-continuous process.

\subsection{Biogas Production Efficacy of the Developed Compact Multi-Layer Membrane Bioreactor (MMBR)}

In the present study, a membrane bioreactor with a novel configuration for biogas production was developed. The designing of the bioreactor entailed the utilization of an uprising plug flow of the substrates between the membrane layers in order to achieve maximal mass transfer and a higher efficacy of the bioreactor. In the reactor, the bacterial cells are entrapped inside a flat hollow rubber ring (thickness $3 \mathrm{~mm}$, diameter $95 \mathrm{~mm}$ ), with membranes on both sides as well as circular stainless steel membrane support rings. This layering is repeated inside the reactor [see (1) in Figure 1]. The substrate fluid flows between the membranes through the bioreactor providing a cross-flow of nutrients and metabolic products, including biogas, over the membrane surfaces. Durapore ${ }^{\circledR}$ membrane 
(hydrophilic PVDF) was used as the membrane reference in this experiment due to their ability to retain the bacterial cells for biogas production [18,19]. The performance of the compact MMBR was compared to the conventional system with freely suspended cells. The key parameters to monitor anaerobic digestion processes are normally biogas production and volatile fatty acid (VFA) accumulation, which gives an indication of how well the digesting bacteria in the system can handle the degradation of a substrate [1,2].

Figure 1. Schematic illustration of the compact multi-layer membrane bioreactor (MMBR). The numbers indicate (1) multi-layer membrane compartment; (2) warm water jacket; (3) water heater; (4) gas flow gauge; (5) digestate wastewater tank; (6) substrate feed tank; (7) peristaltic pump; and (8) control unit system.

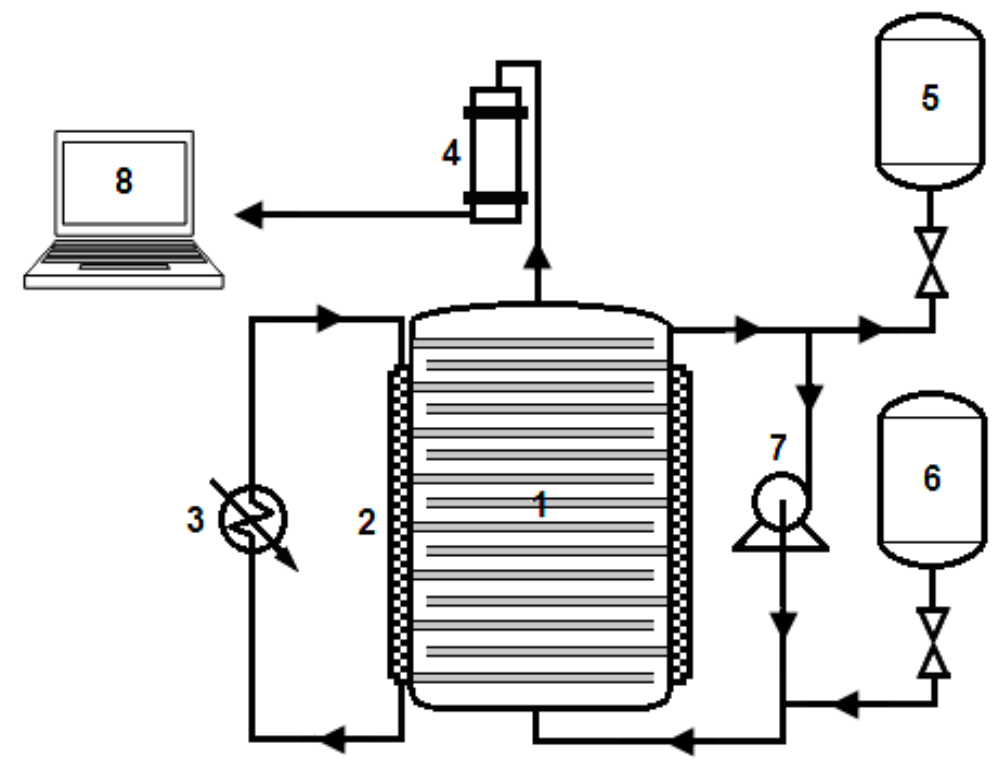

For the conventional reactor with free cells, the digesting bacteria were washed out due to the short retention time of the semi continuous process, and consequently, the biogas production was low (Figure $2 \mathrm{a}$ ). The average daily biogas production while feeding with a low organic loading rate (OLR) (3.07 $\mathrm{g} \mathrm{COD} / \mathrm{L} \cdot$ day) was $225 \mathrm{~mL}$. A gradual increase of the OLR to 6.16 and $8.16 \mathrm{~g} \mathrm{COD} / \mathrm{L} \cdot$ day resulted in reducing the biogas production to 77 and $154 \mathrm{~mL}$, respectively, indicating a decline in the reactor efficacy. When running the MMBR with the commercial membrane, Durapore ${ }^{\circledR}$, there was no wash out of the cells, and the biogas was produced continuously at all three OLRs. The maximum daily biogas productions were 1016, 1670, and $1960 \mathrm{~mL}$ /day at the OLRs 3.08, 6.16, and $8.16 \mathrm{~g}$ $\mathrm{COD} / \mathrm{L} \cdot$ day respectively, on the $3 \mathrm{rd}, 14 \mathrm{th}$, and 20th day of digestion (Figure 2a). Using the MMBR containing PVDF membranes resulted in a higher biogas productivity compared to the conventional system with suspended cells. The VFAs were also analyzed during the anaerobic digestion process from both types of reactors. The magnitude of accumulating VFAs in the effluent gives an indication of the efficacy of the digester performance. The VFAs are the substrate for methanogenic bacteria to produce biogas during the digestion process. Gas production normally increases with increasing concentrations of VFA, and also when the OLR is increased, provided that the cells are capable of converting the organic acids to biogas. When using the MMBR containing PVDF membranes, 
however, the total amount of VFA decreased continuously from the first day of digestion, stabilizing at around $1 \mathrm{~g} / \mathrm{L}$, in spite of increased OLRs (Figure $2 \mathrm{~b}$ ). It means that VFAs were consumed continuously by the retained cells. Furthermore, for the conventional reactor at a high loading rate, the cells were gradually washed out, and the accumulated VFA levels fluctuated during the experimental periods. They decreased during the lowest OLR, but showed an increase followed by a decrease when the two higher loading rates were applied (Figure $2 b$ ). From these results, it can be concluded that anaerobic digestion using a MMBR equipped with PVDF membranes enables a high amount of cells to be retained, so that the VFA can be degraded. On the other hand, the conventional system with free cells fails due to loss of bacterial cells.

Figure 2. Performance of compact multi-layer membrane bioreactor (MMBR) compared to conventional system: (a) Daily biogas volumes produced; (b) Total volatile fatty acids in the bioreactor. The ramped solid lines indicate the organic loading rate and the symbols show the biogas production and total volatile fatty acids in (a) and (b) respectively.
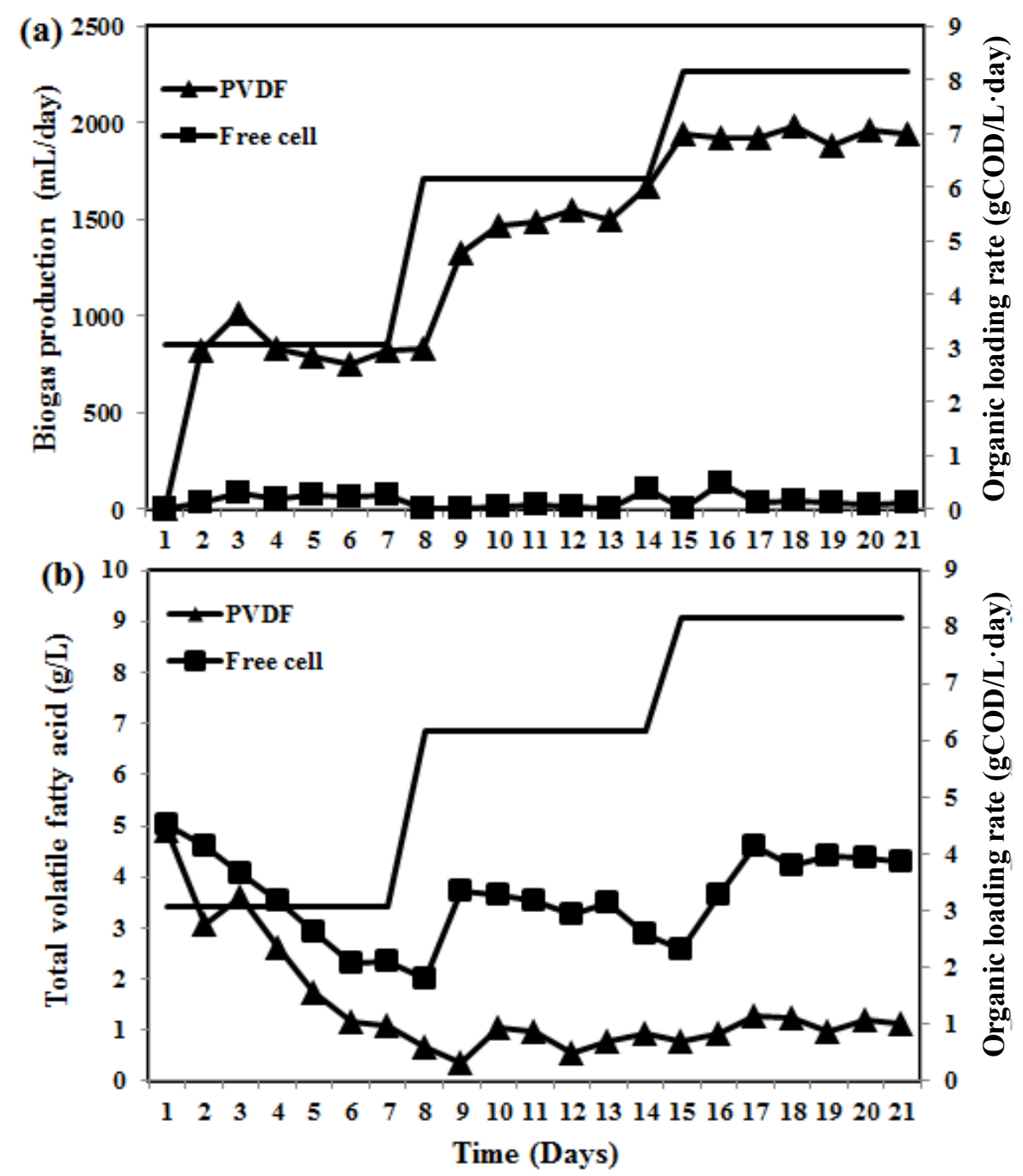

The results of the present study imply a superior performance of the compact MMBR for rapid biogas production when using synthetic membranes, as compared to using a reactor with free cells. The highest production of biogas, along with the lowest accumulation of VFA, was achieved when using the PVDF membranes. 


\subsection{Characteristics of the Developed Synthetic Membranes and Their Efficacy for Enhancing}

\section{Biogas Productivity}

Since methane is not affected by the polarity of water molecules (containing non-polar covalent bonds), but the substrates of the methanogenic microorganisms are water-soluble components, the suitability of different synthetic membranes for use in a compact MMBR for biogas production in anaerobic digestion was investigated. Two methods were employed to synthesize membrane filters based on the polymer polyamide 46. Granulated polyamide 46 was blended with a low molecular weight hydrophilic polymer (PVP) in a solvent to create pores, called polyamide 46 (PA). This type of membrane is called a passive membrane. The other method entailed a functionalization of the polyamide 46 into a homogenous hydroxyethylated derivative, to improve the capillary effect and to reduce bio-fouling, called hydroxyethylated polyamide 46 (HPA). The two methods resulted in the membrane to some extent acquiring polarity.

The previous experiment showed a superior performance of a compact MMBR compared to a conventional system for biogas production. However, the reactor efficacy was highly dependent on the type of membrane filter used. Polyamides have been known as high quality organic materials with high thermal and mechanical resistances. Research efforts are taking benefits of their attributes to increase their manufacturability, permeability and solubility; for example, by making them incorporate other chemicals for specific applications [20]. These would make possible the use of polyamides in different applications and is an important research field [21-26].

The micrograph of HPA (Figure 3) displays a non-homogenous nanoporous membrane (pore size $70 \mathrm{~nm}$ ). The average thickness of the membranes was $0.13 \mathrm{~mm}$ (Table 1). The disordered and uneven spherical surface most probably contains hydroxyl groups $(-\mathrm{OH})$ in the bulk of the polyamide, facilitating the reduction of bio-fouling as observed during the reactor experiments. In contrast, the ordered and smooth surface of the PA (Figure 4) with an average thickness and pore size of about $0.11 \mathrm{~mm}$ and $280 \mathrm{~nm}$ respectively, may enable adsorption of biomass on the surface of the membrane. The asymmetric channels, distributed through the membrane, are probably caused by PVP leaching from the bulk of the polyamide 46 .

Table 1. Comparison of the physical properties of commercial PVDF, HPA membrane, and PA membrane.

\begin{tabular}{ccccccc}
\hline Membrane & $\begin{array}{c}\text { Pore size } \\
(\mathbf{n m})\end{array}$ & $\begin{array}{c}\text { Bubble point } \\
\mathbf{a t} \mathbf{2 0}{ }^{\circ} \mathbf{C} \\
(\mathbf{p s i})\end{array}$ & $\begin{array}{c}\text { Flux at 1.0 bar } \\
\text { and } \mathbf{2 0}{ }^{\circ} \mathbf{C} \\
\left(\mathbf{L} / \mathbf{m}^{\mathbf{2}} \cdot \mathbf{h}\right)\end{array}$ & $\begin{array}{c}\text { Water uptake } \\
\mathbf{a t} \mathbf{2 0}{ }^{\circ} \mathbf{C} \\
(\mathbf{g} / \mathbf{g})\end{array}$ & $\begin{array}{c}\text { Porosity } \\
\mathbf{( \% )}\end{array}$ & $\begin{array}{c}\text { Thickness } \\
(\mathbf{m m})\end{array}$ \\
\hline PVDF & 110 & 155 & 13.36 & 0.093 & 10.551 & 0.125 \\
HPA & 70 & 173 & 1.94 & 0.101 & 7.616 & 0.13 \\
PA & 280 & 43 & 0.389 & 0.051 & 9.642 & 0.11 \\
\hline
\end{tabular}


Figure 3. SEM micrograph of (a) the spherical surface of the HPA membrane, 2000× magnification; (b) Pore distribution on the surface of HPA, 7000× magnification; (c) and (d) Morphology of pores and surface of HPA, 60,000× magnification.
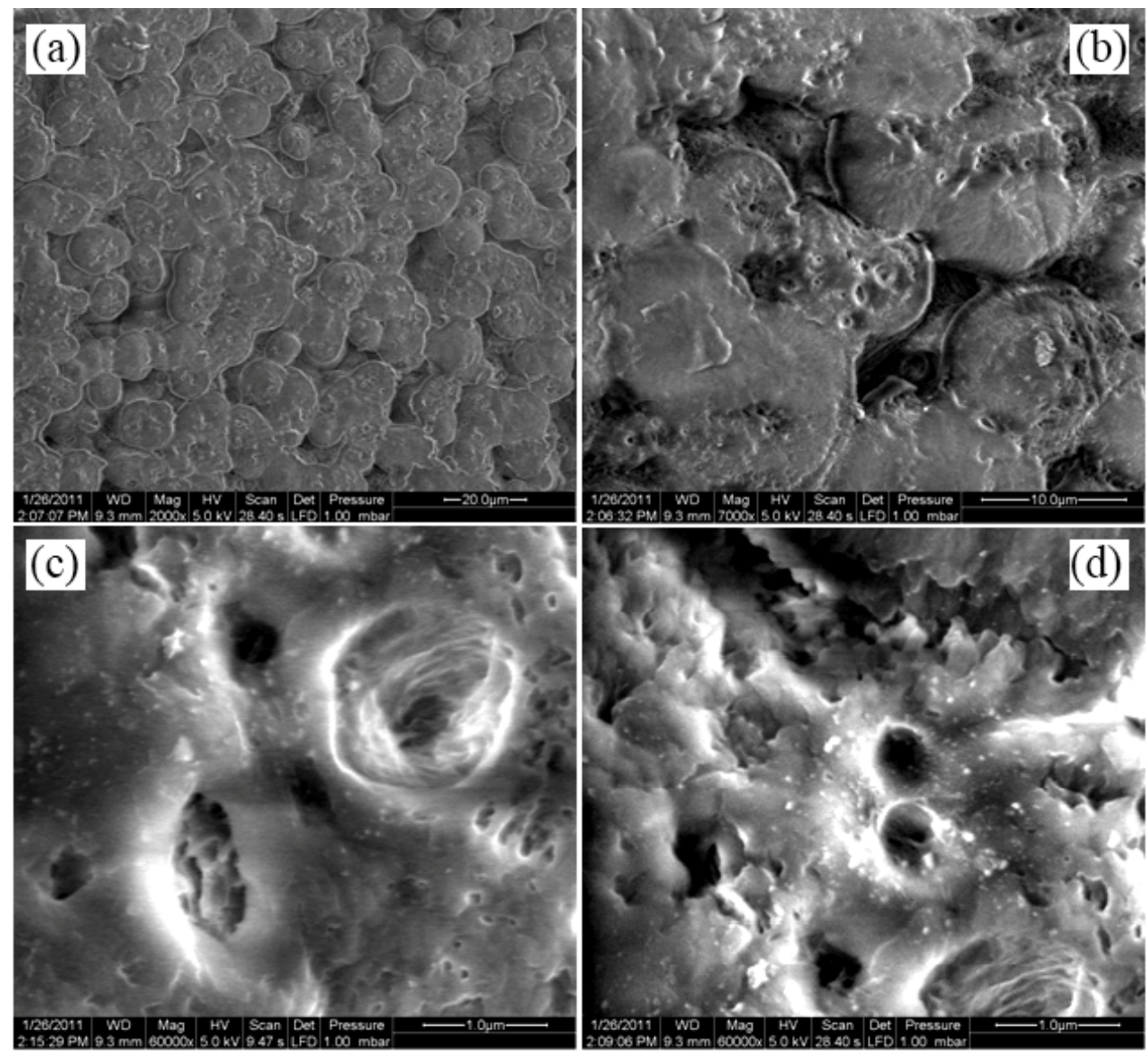

Both developed membranes were installed in a compact MMBR in order to test their efficiency in retaining cells producing biogas. The results are shown in Figure 5a. While working with a compact MMBR using PA membrane which was developed for this experiment as a hydrophobic membrane, the results showed that no wash out of the cells occurred, but the daily biogas production was very low even as the OLR was increased. The daily biogas produced was not significantly higher than for the free cells, with maximum daily biogas produced at 3.08, 6.16 and $8.16 \mathrm{~g} \mathrm{COD} / \mathrm{L} \cdot$ day of 121,50 and $112 \mathrm{~mL}$, respectively. Looking at the total VFA accumulation in the bioreactor using PA, it was higher than in the reactor with the HPA membranes (Figure 5b). The total VFA value with the PA membranes decreased notably when using an OLR of $3.08 \mathrm{~g} \mathrm{COD} / \mathrm{L} \cdot$ day, but increased at the two higher OLRs to about $9 \mathrm{~g} / \mathrm{L}$. This shows that the process using PA was successful in retaining the bacterial cells, but failed to produce biogas. The results may be explained by that PA was synthesized from polyamide 46 with PVP to create pores, but the structure contains no hydrophilic functional groups; hence there is little or no interaction between the mobile phase and the membrane. Although the PA membrane had a larger pore size than the other membranes (Table 1), the flow of nutrients through the membranes was still not good. This was probably an effect of its higher hydrophobicity, leading to fouling of the membrane pores by metabolism of microorganism [13], leading to accumulation of VFA and little or no biogas production. 
Figure 4. Cross-sectional SEM micrographs of the PA membrane: (a) 2500× magnification; (b) Vertical channel distribution of PA 46, 5000× magnification; (c) and (d) Morphology of the pore-wall, 10,000× and 20,000× magnifications.

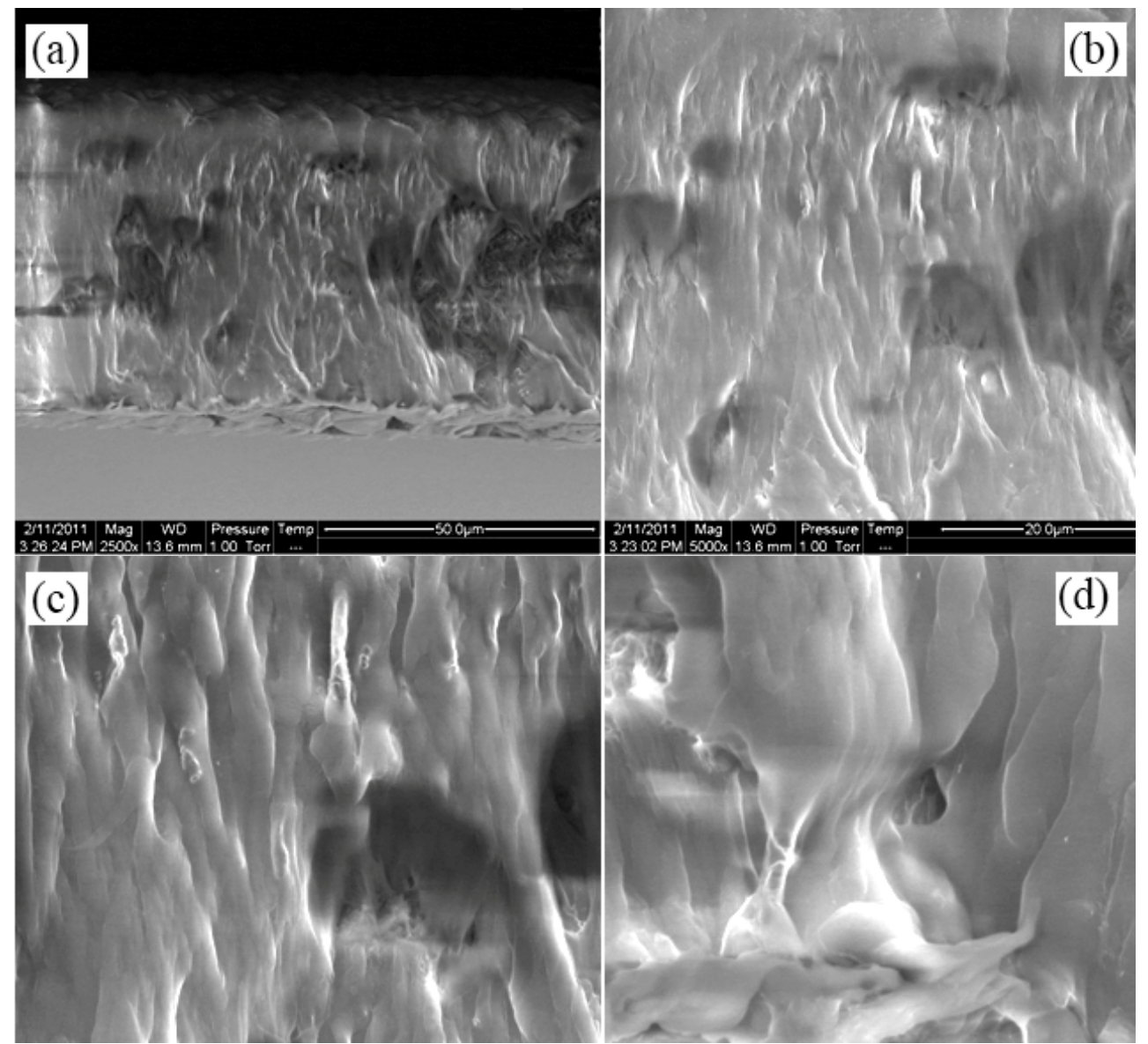

Another synthetic membrane was developed in order to enhance the diffusion of substrates and decreasing the membrane fouling, called HPA. Interestingly, it was obvious that no wash out of the cells occurred, and the biogas production from the membrane bioreactor using HPA increased as the OLR was increased from 3.08 to $6.16 \mathrm{~g} \mathrm{COD} / \mathrm{L} \cdot$ day. The average daily biogas production at 3.08 and $6.16 \mathrm{~g} \mathrm{COD} / \mathrm{L}$-day were 1102 and $1633 \mathrm{~mL}$ per day, respectively. This is at the same level of biogas productivity as the reactor system with the reference membrane (PVDF) (Figure 2). However, the biogas yield started to decrease slightly after 18 days of digestion, with an OLR of $8.16 \mathrm{~g} \mathrm{COD/L}$-day. The daily biogas produced on the last day was $1306 \mathrm{~mL}$, which can be compared with the highest production of $1863 \mathrm{~mL}$ on the 18th day (Figure 5a). As well as the total amount of VFA when using HPA (Figure 5b) and PVDF (Figure 2b) in this experiment were almost similar at the OLRs of 3.08 and $6.16 \mathrm{~g} \mathrm{COD} / \mathrm{L} \cdot$ day, but the VFA-level of effluence from bioreactor with HPA, however, increased to $5 \mathrm{~g} / \mathrm{L}$ on the last day of digestion. HPA, exhibited a high flow rate of nutrients (VFA), resulting in high biogas production up to 18 days of digestion. After that, the - $\mathrm{OH}$ groups on the HPA tentatively started reacting with anions of the carboxylic fatty acids, thereby blocking the hydroxyl groups on the polymer chain. In addition, the HPA membrane's durability decreased slightly during the last week of digestion. This led to loss of some cells, therefore the decrease in efficacy of the reactor system was likely an effect of less bacterial cells towards the end of the experiment. 
Figure 5. Efficacy of PA and HPA in compact MMBR: (a) Daily biogas volume produced; (b) Total volatile fatty acids. The ramped solid lines indicate the organic loading rate and the symbols show the biogas production and total volatile fatty acids in (a) and (b) respectively.

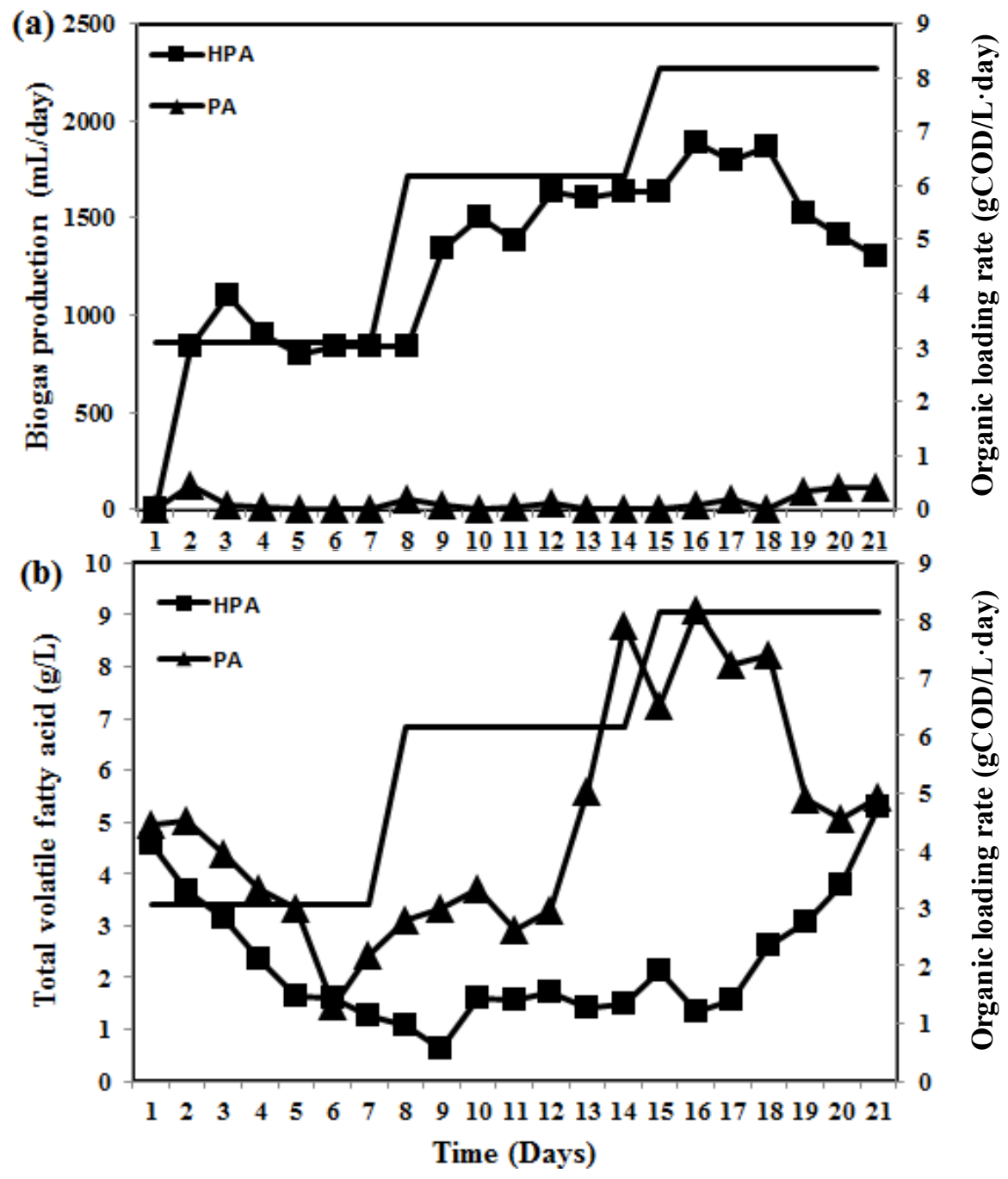

Based on the above results, we conclude that polyamide 46-based membranes can be synthesized and used to retain cells in a compact MMBR for enhancing the biogas production. However, the polarity of the membrane is an important factor for biogas production. The hydrophobic PA was not suitable for biogas production, while the HPA was able to transfer VFAs and release biogas at levels comparable to the commercial reference (hydrophilic PVDF membranes), while retaining the cells.

\section{Experimental}

\subsection{Anaerobic Culture and Medium}

An anaerobic culture of methane-producing microorganisms was obtained from a $3000-\mathrm{m}^{3}$ municipal solid waste digester, operating under thermophilic $\left(55^{\circ} \mathrm{C}\right)$ conditions (Borås Energy \& Environment $\mathrm{AB}$, Borås, Sweden). The inoculum was incubated at $55{ }^{\circ} \mathrm{C}$ for 3 days, to keep the microorganism active while consuming the carbon source provided by the inoculum. After incubation, 
the inoculum was filtered through a sieve $(1 \mathrm{~mm}$ pore size $)$ to remove large particles. The digesting sludge was then centrifuged at $14,000 \times \mathrm{g}$ for $10 \mathrm{~min}$ to separate the inoculum, the digesting and methane producing microorganisms, which was loaded between the membrane layers. The substrate used was a mixture of acetate, propionate, butyrate, methanol, and glucose in a basal medium (BM, buffered to $\mathrm{pH} 7.0 \pm 0.2$ with $\mathrm{NaHCO}_{3}$ ), at a concentration ratio of $3: 1: 1: 1: 1$, respectively [27].

\subsection{Synthetic Membranes Preparation}

In this experiment, three different kinds of synthetic membranes were investigated. PVDF was purchased from Millipore as a commercial reference membrane, and the others were developed and made in house for this experiment using the casting solution method forming membranes based on polyamide 46 and hydroxyethylated PA 46.

Durapore ${ }^{\circledR}$ membrane filters $(P V D F)$ : The membrane was provided by Millipore AB (Solna, Sweden) and used as commercial reference. This membrane comprises a hydrophilic polyvinylidene fluoride (PVDF) that provides high flow rates and throughput, low extractability, broad chemical compatibility, and possibility of operation at high temperature. Its pore size and thickness were $0.1 \mu \mathrm{m}$ and $125 \mathrm{~mm}$, respectively.

Hydroxyethylated polyamide 46 (HPA) membranes: The granulated polyamide 46 (Stanly TW300, $\mathrm{Mn} \sim 24,000 \mathrm{~g} / \mathrm{mol}$ ) was supplied by DSM Engineering Plastics (DSM Scandinavia AB, Åstorp, Sweden). The granulated polyamide was heated up to $50 \pm 2{ }^{\circ} \mathrm{C}$ in an oven for $3 \mathrm{~h}$. After desiccation to stabilize the weight, $10 \mathrm{~g}$ of dried polyamide 46 was gradually mixed with $80 \mathrm{~mL}$ formic acid ( $\geq 98 \%$ purity, $1.22 \mathrm{~g} / \mathrm{mL}$ at $\left.25{ }^{\circ} \mathrm{C}\right)$, followed by addition of $20 \mathrm{~mL} 99.8 \%$ methanol $\left(0.7918 \mathrm{~g} / \mathrm{mL}\right.$ at $\left.25{ }^{\circ} \mathrm{C}\right)$ and $10 \mathrm{~mL}$ dimethyl sulfoxide (DMSO) ( $\geq 99.5 \%$ purity, $1.10 \mathrm{~g} / \mathrm{mL}$ at $25^{\circ} \mathrm{C}$ ). The solution was heated at $60 \pm 2{ }^{\circ} \mathrm{C}$ for $15 \mathrm{~min}$, where after $1.13 \mathrm{~g}$ anhydrous aluminum chloride $\left(\mathrm{AlCl}_{3}\right)$ (purity $\geq 99.9 \%$ ) was added, and then kept at $75 \pm 2{ }^{\circ} \mathrm{C}$ for $1 \mathrm{~h}$. After cooling to room temperature, $12 \mathrm{~mL}$ acetaldehyde ( $\geq 99 \%$ purity, $0.785 \mathrm{~g} / \mathrm{mL}$ at $25^{\circ} \mathrm{C}$ ) was added slowly. The mixture was heated at $55 \pm 2{ }^{\circ} \mathrm{C}$ for $30 \mathrm{~min}$, after which it was allowed to cool to room temperature. The solution was further mixed with $300 \mathrm{~mL}$ methanol $(80 \%)$ and stirred for $15 \mathrm{~min}$. The suspended modified polymer was separated from the solution by centrifugation at $8000 \times \mathrm{g}$ for $5 \mathrm{~min}$. The last step was repeated after mixing with $200 \mathrm{~mL}$ methanol (80\%) and $15 \mathrm{~mL}$ ammonium hydroxide (20\%) to remove impurities. After these procedures, the modified polymer was dried at $50{ }^{\circ} \mathrm{C}$ for $3 \mathrm{~h}$. Then, $10 \mathrm{~g}$ of modified polymer was dissolved in a mixture of $90 \mathrm{~mL}$ formic acid and $10 \mathrm{~mL}$ water. The solution was poured into a glass cast $(35 \times 30 \times 2 \mathrm{~cm})$. The polymer solution was then kept in an oven at $45{ }^{\circ} \mathrm{C}$ for $6 \mathrm{~h}$. The solidified membrane sheet was removed by immersing in water. After drying the membrane films at room temperature, they were subjected to hot-pressing in order to acquire flat sheets.

Polyamide 46 (PA) membranes: Granulated polyamide $46(10 \mathrm{~g})$ were dispersed in $80 \mathrm{~mL}$ formic acid ( $\geq 98 \%$ ) followed by the adding of $4 \mathrm{~g}$ polyvinylpyrrolidone (PVP 10 , average $\mathrm{M}_{\mathrm{n}} \sim 10,000 \mathrm{~g} / \mathrm{mol}$ ) in $30 \mathrm{~mL}$ methanol (99.8\%) [28]. The solution was then heated up at $50{ }^{\circ} \mathrm{C}$ to acquire a homogenous solution, after which it was transferred into a glass cast $(35 \times 30 \times 2 \mathrm{~cm})$ and dried in an oven at $50{ }^{\circ} \mathrm{C}$ for $6 \mathrm{~h}$. The cast was immersed in warm water $\left(60 \pm 5^{\circ} \mathrm{C}\right)$ for $2 \mathrm{~h}$ to leach away PVP residues from the polyamide matrix, and also to facilitate the removal of the membrane from the glass cast. This process was repeated three times with plenty of warm water in order to secure a complete elimination of PVP 
residues in the bulk of membrane films. The dried sheets were subjected to hot-pressing and then cut to fit the bed diameter of the bioreactor.

\subsection{Semi-Continuous Anaerobic Digestion Process}

The reactors were made in house from Plexiglas ${ }^{\circledR}$ sheet, had a total inner volume of $1.5 \mathrm{~L}$ and were fitted with rubber seals and an outlet for the biogas (Figure 1). In this experiment, 17 membrane layers containing a total of $153 \mathrm{~g}$ inoculum were added into $800 \mathrm{~mL}$ medium in each reactor. In parallel, the same amount of inoculum was used in a reference reactor using free cells. Thermophilic conditions were maintained at $55 \pm 1{ }^{\circ} \mathrm{C}$ throughout the process by passing warm water from a water bath through the reactor jacket (Figure 1). The OLR was then gradually increased by increasing the volume of medium fed (Table 2). Each loading rate was maintained for 7 days, giving a total digestion process of 21 days. During the digestion, the medium was circulated continuously with a flow rate of $150 \mathrm{~mL} / \mathrm{min}$. The first experiment was performed to test the efficacy of a compact MMBR using PVDF membrane and compared to a conventional reactor with free cell. Another was performed in order to investigate the efficacy of the developed synthetic membranes, PA and HPA, for biogas production.

Table 2. Experimental set up of OLR conditions during the semi-continuous digestion process of testing free and encased methane-producing microorganisms.

\begin{tabular}{cccc}
\hline $\begin{array}{c}\text { Organic loading rate } \\
(\mathbf{O L R})(\mathbf{g ~ C O D} / \mathbf{L} \cdot \text { day) }\end{array}$ & $\begin{array}{c}\text { Working volume } \\
\text { of reactor }(\mathbf{m L})\end{array}$ & $\begin{array}{c}\text { Synthetic medium } \\
\text { strength }(\mathbf{g ~ C O D} / \mathbf{L})\end{array}$ & $\begin{array}{c}\text { Flow rate of medium } \\
(\mathbf{m L} / \text { day })\end{array}$ \\
\hline 3.08 & 800 & 9.33 & 264 \\
6.16 & 800 & 9.33 & 528 \\
8.16 & 800 & 9.33 & 700 \\
\hline
\end{tabular}

\subsection{Analytical Methods}

The morphology of the membranes was studied using environmental scanning electron microscope (ESEM-FEI Quanta 200F, Hillsboro, OR, USA) at 1.0 torr and $10 \mathrm{kV}$ at room temperature. Each sample was adhered to a conductive carbon tab, which was placed on an aluminum tilt in the vacuum chamber. Porosity (pore volume distributions) of the membranes which is directly related to the total pore volume was determined by the degree of water uptake (1). To reach equilibrium swelling, the dried membranes were immersed in ultra-pure water overnight at $20^{\circ} \mathrm{C}$, after which the excess water was removed using tissue paper, and the membranes rapidly weighed $(W)$. After that, the membranes were dried in an oven for $2 \mathrm{~h}$ at $105{ }^{\circ} \mathrm{C}$ and weighed again $\left(W_{0}\right)$. The degree of water uptake at $20{ }^{\circ} \mathrm{C}$ was calculated using the equation:

$$
\text { Water uptake }\left(20^{\circ} \mathrm{C}\right)=\frac{W-W_{0}}{W_{0}}
$$

Biogas volume was automatically recorded using "Automatic Methane Potential Test System" (AMPTS, Bioprocess Control AB, Lund, Sweden). Methane and carbon dioxide were measured regularly; using a gas chromatograph (Auto System, Perkin-Elmer, Waltham, MC, USA); equipped with a packed column (Prorapack, Perkin-Elmer, 6' $\times 1.8^{\prime \prime}$ OD, 80/100 Mesh) and a thermal 
conductivity detector (Perkin-Elmer, Waltham, MC, USA) with an injection temperature of $150{ }^{\circ} \mathrm{C}$. The carrier gas was nitrogen; with a flow rate of $20 \mathrm{~mL} / \mathrm{min}$ at $60{ }^{\circ} \mathrm{C}$. A $250 \mu \mathrm{L}$ gastight syringe (VICI; Precision Sampling Inc., Baton Rouge, LA, USA) was used for the gas sampling. The obtained peak area was compared with a standard gas analyzed at the same condition (STP, standard conditions for temperature and pressure, $0{ }^{\circ} \mathrm{C}$ and $101.325 \mathrm{kPa}$ ). The VFAs in the reactor effluent were analyzed using an HPLC system (Waters, Milford, MA, USA) equipped with an ion-exchange column (Aminex HPX-87H, Bio-Rad, Hercules, CA, USA) working at $60{ }^{\circ} \mathrm{C}$; and a UV detector (Waters, Sollentuna, Sweden). The eluent; $5 \mathrm{mM}$ sulfuric acid; was set at a flow rate of $0.6 \mathrm{~mL} / \mathrm{min}$.

\section{Conclusions}

Retaining biogas-producing bacteria in synthetic membranes using a MMBR, improved the digestion performance at high dilution and OLRs. Cross-flow of the liquid on the membrane surface, and substrate diffusion through the membranes with no pressure driving force was sufficient for the bacteria to receive the nutrients and to produce biogas. The choice of membrane type was critical. The developed hydrophobic PA was not adequate for biogas production, while the synthesized hydrophilic HPA and the commercial PVDF membranes were able to transfer nutrients and metabolites, while retaining the cells.

\section{Acknowledgments}

This work was financially supported by the Swedish Research Council and the European Commission program EM EuroAsia.

\section{Conflicts of Interest}

The authors declare no conflict of interest.

\section{References}

1. Deublein, D.; Steinhauser, A. Biogas from Waste and Renewable Resources; Wiley-VCH Verlag GmbH \& Co. KGaA: Weinheim, Germany, 2008; pp. 49-50.

2. Gerardi, M.H. The Microbiology of Anaerobic Digesters; John Wiley \& Sons Inc: Hoboken, NJ, USA, 2003.

3. Huelgas, A.; Funamizu, N. Flat-plate submerged membrane bioreactor for the treatment of higher-load graywater. Desalination 2010, 250, 162-166.

4. Das, D. Advances in biohydrogen production processes: An approach towards commercialization. Int. J. Hydrog. Energy 2009, 34, 7349-7357.

5. Gassanova, L.G.; Netrusov, A.I.; Teplyakov, V.V.; Modigell, M. Fuel gases from organic wastes using membrane bioreactors. Desalination 2006, 198, 56-66.

6. Kumar, N.; Das, D. Continuous hydrogen production by immobilized Enterobacter cloacae IIT-BT 08 using lignocellulosic materials as solid matrices. Enzym. Microb. Technol. 2001, 29, 280-287.

7. Show, K.-Y.; Lee, D.-J.; Chang, J.-S. Bioreactor and process design for biohydrogen production. Bioresour. Technol. 2011, 102, 8524-8533. 
8. Lee, D.-Y.; Li, Y.-Y.; Noike, T. Influence of solids retention time on continuous $\mathrm{H}_{2}$ production using membrane bioreactor. Int. J. Hydrog. Energy 2010, 35, 52-60.

9. Lee, D.-Y.; Li, Y.-Y.; Noike, T. Continuous $\mathrm{H}_{2}$ production by anaerobic mixed microflora in membrane bioreactor. Bioresour. Technol. 2009, 100, 690-695.

10. Jeong, E.; Kim, H.-W.; Nam, J.-Y.; Shin, H.-S. Enhancement of bioenergy production and effluent quality by integrating optimized acidification with submerged anaerobic membrane bioreactor. Bioresour. Technol. 2010, 101, S7-S12.

11. Padmasiri, S.I.; Zhang, J.; Fitch, M.; Norddahl, B.; Morgenroth, E.; Raskin, L. Methanogenic population dynamics and performance of an anaerobic membrane bioreactor (AnMBR) treating swine manure under high shear conditions. Water Res. 2007, 41, 134-144.

12. Baker, W.R. Membrane Technology and Applications; John Wiley \& Sons Inc.: Hoboken, NJ, USA, 2000.

13. Judd, S.; Judd, C. The MBR Book-Priciples and Applications of Membrabe Bioreactors for Water and Waste Water Treatment, 2nd, ed.; Elsevier Ltd.: Burlington, MA, USA, 2011; p. 519.

14. Chen, H.C. Up-flow attached-bed bioreactor for continuous ethanol fermentation. Biotechnol. Prog. 1991, 7, 311-314.

15. Joshi, S.; Yamazaki, H. Film fermentor for ethanol production by yeast immobilized on cotton cloth. Biotechnol. Lett. 1984, 6, 797-802.

16. Shiratori, H.; Ikeno, H.; Ayame, S.; Kataoka, N.; Miya, A.; Hosono, K.; Beppu, T.; Ueda, K. Isolation and characterization of a new Clostridium sp. that performs effective cellulosic waste digestion in a thermophilic methanogenic bioreactor. Appl. Environ. Microbiol. 2006, 72, 3702-3709.

17. Gu, J.-D.; Eberiel, D.T.; McCarthy, S.P.; Gross, R.A. Cellulose acetate biodegradability upon exposure to simulated aerobic composting and anaerobic bioreactor environments. J. Environ. Polymer Degrad. 1993, 1, 143-153.

18. Youngsukkasem, S.; Rakshit, K.S.; Taherzadeh, M.J. Biogas production by encapsulated methane producing bacteria. Bioresources 2012, 7, 56-65.

19. Youngsukkasem, S.; Akinbomi, J.; Rakshit, S.K.; Taherzadeh, M.J. Biogas production by encased bacteria in synthetic membranes: Protective effects in toxic media and high loading rates. Environ. Technol. 2013, 34, 1-8.

20. García, J.M.; García, F.C.; Serna, F.; de la Peña, J.L. High-performance aromatic polyamides. Prog. Polymer Sci. 2010, 35, 623-686.

21. Gabelich, C.J.; Frankin, J.C.; Gerringer, F.W.; Ishida, K.P.; Suffet, I.H. Enhanced oxidation of polyamide membranes using monochloramine and ferrous iron. J. Membr. Sci. 2005, 258, 64-70.

22. Espeso, J.; Lozano, A.E.; de la Campa, J.G.; de Abajo, J. Effect of substituents on the permeation properties of polyamide membranes. J. Membr. Sci. 2006, 280, 659-665.

23. Jin, Y.; Su, Z. Effects of polymerization conditions on hydrophilic groups in aromatic polyamide thin films. J. Membr. Sci. 2009, 330, 175-179.

24. Louie, J.S.; Pinnau, I.; Reinhard, M. Effects of surface coating process conditions on the water permeation and salt rejection properties of composite polyamide reverse osmosis membranes. J. Membr. Sci. 2011, 367, 249-255. 
25. Mitrouli, S.T.; Karabelas, A.J.; Isaias, N.P.; Al Rammah, A.S. Application of hydrophilic macromolecules on thin film composite polyamide membranes for performance restoration. Desalination 2011, 278, 105-116.

26. Shin, D.H.; Kim, N.; Lee, Y.T. Modification to the polyamide TFC RO membranes for improvement of chlorine-resistance. J. Membr. Sci. 2011, 376, 302-311.

27. Isci, A.; Demirer, G.N. Biogas production potential from cotton wastes. Renew. Energy 2007, 32, $750-757$.

28. Lhommeau, C.; Toillon, S.; Pith, T.; Kessler, L.; Jesser, C.; Pinget, M. Polyamide 4,6 membranes for the encapsulation of Langerhans islets: Preparation, physico-chemical properties and biocompatibility studies. J. Mater. Sci. Mater. Med. 1997, 8, 163-174.

(C) 2013 by the authors; licensee MDPI, Basel, Switzerland. This article is an open access article distributed under the terms and conditions of the Creative Commons Attribution license (http://creativecommons.org/licenses/by/3.0/). 